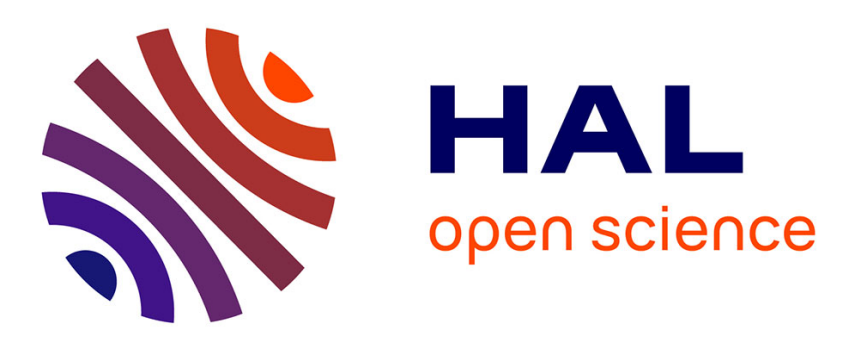

\title{
Cold electron heating by EMIC waves in the plasmaspheric plume with observations of the Cluster satellite
}

Zhigang Yuan, Ying Xiong, Shiyong Huang, Xiaohua Deng, Ye Pang, Meng Zhou, Iannis Dandouras, Jean-Gabriel Trotignon, Andrew N. Fazakerley, Elizabeth Lucek

\section{To cite this version:}

Zhigang Yuan, Ying Xiong, Shiyong Huang, Xiaohua Deng, Ye Pang, et al.. Cold electron heating by EMIC waves in the plasmaspheric plume with observations of the Cluster satellite. Geophysical Research Letters, 2014, 41 (6), pp.1830-1837. 10.1002/2014GL059241 . insu-01174404

\section{HAL Id: insu-01174404 https://hal-insu.archives-ouvertes.fr/insu-01174404}

Submitted on 9 Jul 2015

HAL is a multi-disciplinary open access archive for the deposit and dissemination of scientific research documents, whether they are published or not. The documents may come from teaching and research institutions in France or abroad, or from public or private research centers.
L'archive ouverte pluridisciplinaire HAL, est destinée au dépôt et à la diffusion de documents scientifiques de niveau recherche, publiés ou non, émanant des établissements d'enseignement et de recherche français ou étrangers, des laboratoires publics ou privés. 


\section{Geophysical Research Letters}

\section{RESEARCH LETTER}

10.1002/2014GL059241

Key Points:

- In-situ evidences of cold electron heating with Landau damping of EMIC waves

- Modification of EMIC waves by density irregularities in the plume

- Mechanism of energy transfer from RC ions to cold plasmaspheric electrons

Correspondence to:

Z. Yuan,

y_zgang@vip.163.com

Citation:

Yuan, Z., Y. Xiong, S. Huang, X. Deng, Y. Pang, M. Zhou, I. Dandouras, J. G. Trotignon, A. N. Fazakerley, and E. Lucek (2014), Cold electron heating by EMIC waves in the plasmaspheric plume with observations of the Cluster satellite, Geophys. Res. Lett., 41, 1830-1837, doi:10.1002/2014GL059241.

Received 8 JAN 2014 Accepted 22 FEB 2014 Accepted article online 3 MAR 2014 Published online 18 MAR 2014

\section{Cold electron heating by EMIC waves in the plasmaspheric plume with observations of the Cluster satellite}

\author{
Zhigang Yuan ${ }^{1}$, Ying Xiong ${ }^{1,2}$, Shiyong Huang ${ }^{1}$, Xiaohua Deng ${ }^{3}$, Ye Pang ${ }^{3}$, Meng Zhou ${ }^{3}$, \\ lannis Dandouras ${ }^{4}$, Jean Gabriel Trotignon ${ }^{5}$, Andrew N. Fazakerley ${ }^{6}$, and Elizabeth Lucek \\ ${ }^{1}$ School of Electronic Information, Wuhan University, Wuhan, China, ${ }^{2}$ School of Computer Science, Hubei University \\ of Technology, Wuhan, China, ${ }^{3}$ Institute of Space Science and Technology, Nanchang University, Nanchang, China, \\ ${ }^{4}$ Institut de Recherche en Astrophysique et Planétologie, UPS-CNR, Toulouse, France, ${ }^{5}$ Laboratoire de Physique \\ et Chimie de I'Environnement et de I'Espace (LPC2E), CNRS and University of Orléans, Orléans, France, ${ }^{6}$ Mullard \\ Space Sciences Laboratory, University College London, London, UK, ${ }^{7}$ Blackett Laboratory, Imperial College London, \\ London, UK
}

Abstract We report in situ observations by the Cluster spacecraft of plasmaspheric electron heating in the plasmaspheric plume. Electron heating events were accompanied by enhancements of electromagnetic ion cyclotron (EMIC) waves in the increased density ducts on the negative density gradient side for two substructures of the plasmaspheric plume. Electron heating is much stronger for the pitch angle of $0^{\circ}$ and $180^{\circ}$ than for the pitch angle of $90^{\circ}$. Theoretical calculations of the Landau resonant interaction between electrons and observed EMIC waves demonstrate that Landau damping of oblique EMIC waves is a reasonable candidate to heat cold electrons in the presence of $\mathrm{O}^{+}$ions in the outer boundary of the plasmaspheric plume. Therefore, this observation is considered in situ evidence of plasmaspheric electron heating through Landau damping of EMIC waves in plasmaspheric plumes.

\section{Introduction}

During geomagnetic storms, temperature enhancements of the subauroral topside ionospheric electrons are an important feature which drives the Stable Auroral Red (SAR) arc [Chandra et al., 1972; Kozyra et al., 1997]. A downward heat flux generated within the overlap of the ring current (RC) and plasmasphere is caused by the energy transfer from the ring current to the plasmaspheric electrons, leading to temperature enhancements of the subauroral topside ionospheric electrons [Brace et al., 1988; Kozyra et al., 1997]. The dominant process of energy transfer from the ring current to cold plasmaspheric electrons has yet to be definitely established. There are three leading mechanisms: Coulomb collisions of plasmaspheric electrons with RC ions producing a heated plasmaspheric electron population [Cole, 1965, 1975; Kozyra et al., 1987; Fok et al., 1993]; heating the plasmaspheric electrons through resonant Landau damping of electromagnetic ion cyclotron (EMIC) waves generated by RC ions [Cornwall et al., 1971; Thorne and Horne, 1992; Zhou et al., 2013]; and kinetic Alfvén waves directly accelerating plasmaspheric electrons into the ionosphere through the parallel electric field associated with the waves [Hasagawa and Mima, 1978]. Evidences of ion cyclotron, kinetic Alfvén waves in association with events of ionospheric electron heating elsewhere have been reported [Lundblad and Søraas, 1978; Erlandson et al., 1993; Lanzerotti et al., 1978; Mishin and Burke, 2005]. Although the energy source of plasmaspheric electron heating is assumed to be in the magnetosphere [Kozyra et al., 1997], to our knowledge few in situ evidence of plasmaspheric electron heating in the plasmaspheric plume has been reported.

Yuan et al. [2012] presented wave and particle observations by the Cluster C1 satellite in a plasmaspheric plume in the recovery phase of the geomagnetic storm on 18 July 2005. In this case, in the outer boundary of the plasmaspheric plume Cluster $\mathrm{C} 1$ observed that RC ions were scattered into the loss cone by EMIC waves [Yuan et al., 2012]. In this letter, we focus on in situ observations of plasmaspheric electron heating in the plasmaspheric plume for the case during the geomagnetic storm on 18 July 2005. In section 2, we present observations from the Cluster C1 on 18 July 2005. In section 3, these results are discussed and compared with other references. Finally, a summary is given. 


\section{Observations}

An overview of Cluster C1 data including the electron number density, the energy-time spectrograms of electrons and ions, the magnetic field, and power spectral density of one of the perpendicular components of the perturbed magnetic field during the time interval from 14:00 UT to 15:06 UT is shown in Figure 1. Figure 1a shows a plume crossed by Cluster C1 during an inbound plasmasphere pass on 18 July 2005 with MLAT from $-40^{\circ}$ to $-25^{\circ}$. Darrouzet et al. [2008] have identified the region of the two density enhancements shown in Figure 1a as substructures of a plasmaspheric plume. In our previous paper [Yuan et al., 2012], using the TS05 model [Tsyganenko and Sitnov, 2005] we have located the outer and inner boundaries of the plume at $L$ values of 9.4 and 7.4 and MLT values of 15:14 and 15:48.

Figures $1 \mathrm{~b}-1 \mathrm{~d}$ show PEACE electron energy-time spectrogram at pitch angle of $0^{\circ}, 180^{\circ}$, and $90^{\circ}$, respectively. As denoted by vertical solid lines in Figure 1, the electron flux with energies of hundreds of $\mathrm{eV}$ shows enhancements, implying two obvious events of occurrence of heated plasmaspheric electrons. For the two events of electron heating denoted by vertical solid lines, the electron heating is much stronger for the pitch angle of $0^{\circ}$ and $180^{\circ}$ than for the pitch angle of $90^{\circ}$. This electron heating occurred in the outer boundary of the plasmaspheric plume. As shown in Figure 1e, the pitch angle distribution of electrons at energy of $73 \mathrm{eV}$ also displayed enhancements of flux during the two events of the electron heating. During the first event, the pitch angle distribution became anisotropic for electrons at energy of $73 \mathrm{eV}$ with enhancements of EMIC waves shown in Figure 1h. Especially, the pitch angle distribution displayed significant anisotropy during the second event, i.e., appearance of a field aligned population. In the plume but outside of the electron heating region between 14:36 and 14:48 UT, the most intense electron fluxes for the pitch angle of $0^{\circ}$ and $180^{\circ}$ below $20 \mathrm{eV}$ are due to spacecraft secondary-and photoelectrons emitted from the spacecraft themselves [Owen et al., 2001]. Therefore, during the interval denoted by black vertical solid lines in Figure 1, the electron flux with energies of 7-20 eV should include heated electrons and spacecraft secondary- and photo-electrons.

In the plasmaspheric plume, as shown in Figure 1f, the ring current is revealed by the presence of strong fluxes of high-energy ( $>10 \mathrm{keV}$ ) trapped ions [Vallat et al., 2004]. The average magnetic field is calculated by a $25.6 \mathrm{~s}$ running average with the high-resolution magnetic field. Perturbed magnetic field is calculated by subtracting average magnetic field from the high-resolution magnetic field. The average magnetic field is considered the ambient or static magnetic field where Cluster $C 1$ is located. As shown in Figure $1 \mathrm{~g}$, two perpendicular components $\left(\Delta \mathrm{B}_{\mathrm{t} 1}\right.$ and $\left.\Delta \mathrm{B}_{\mathrm{t} 2}\right)$ and the field-aligned component $\left(\Delta \mathrm{B}_{\mathrm{FA}}\right)$ in field-aligned coordinates of perturbed magnetic field are denoted by red, blue and green solid lines respectively. During two electron heating events, Figure $1 \mathrm{~g}$ shows that the amplitude of perturbed magnetic field increases. At the same time, the transverse component $\Delta B_{t 2}$ of perturbed magnetic field is much stronger than the $\Delta \mathrm{B}_{\mathrm{FA}}$ component, which means that the direction of the perturbed magnetic field is nearly perpendicular to the ambient magnetic field. As the strongest component of perturbed magnetic field, $\Delta \mathrm{B}_{\mathrm{t} 2}$ is used to obtain the power spectral density through fast Fourier transforms (FFTs) with $25.6 \mathrm{~s}$ data intervals. As the power spectral density of $\Delta \mathrm{B}_{\mathrm{t} 2}$ is shown in Figure $1 \mathrm{~h}$, during the interval denoted by the right vertical lines, the pulsation frequencies lie in the range of $0.1-0.5 \mathrm{~Hz}$, i.e. in the Pc1-2 band.

Yuan et al. [2012] studied the interval denoted by the right two vertical solid lines and identified the waves in the Pc1-2 band as EMIC waves and demonstrated that those EMIC waves can scatter ring currents into the loss cone. Therefore, this study focuses on the second event heating. In order to study the polarization characteristics of Pc1-2 waves observed by Cluster $C 1$, we recombine the two transverse components $\left(\Delta B_{t 1}\right.$ and $\left.\Delta \mathrm{B}_{\mathrm{t} 2}\right)$ into left- and right-hand polarized components $\left(\mathrm{B}_{\mathrm{r}}=\Delta \mathrm{B}_{\mathrm{t} 1}+i \Delta \mathrm{B}_{\mathrm{t} 2}\right.$ and $\left.\mathrm{B}_{\mathrm{l}}=\Delta \mathrm{B}_{\mathrm{t} 1}-i \Delta \mathrm{B}_{\mathrm{t} 2}\right)$. Figure $2 \mathrm{a}$ shows power spectrums of three components of perturbed magnetic field in the field-aligned coordinates during the interval of 14:51:36-14:52:28 UT, in the interval denoted by right vertical solid lines in Figure 1. The $\mathrm{He}^{+}$and $\mathrm{O}^{+}$ion gyrofrequencies $\left(\mathrm{f}_{\mathrm{He}+\mathrm{eq}}, \mathrm{f}_{\mathrm{O}+\mathrm{eq}}\right)$ at the equatorial plane projection of Cluster trajectories along the magnetic field lines are calculated using the TS05 model [Tsyganenko and Sitnov, 2005]. The frequency band of Pc1 waves denoted by two vertical solid lines in Figure 2a lies in the frequency range of $0.20-0.4 \mathrm{~Hz}$, between the $\mathrm{O}^{+}$ion gyrofrequency $\left(\mathrm{f}_{\mathrm{O}+\mathrm{eq}}\right)$ and the $\mathrm{He}^{+}$ion gyrofrequency $\left(\mathrm{f}_{\mathrm{He}+\mathrm{eq}}\right)$ at the equatorial plane, identified as EMIC waves of $\mathrm{He}^{+}$branch generated by anisotropic ring current ions in the equatorial plane [Yuan et al., 2012]. 


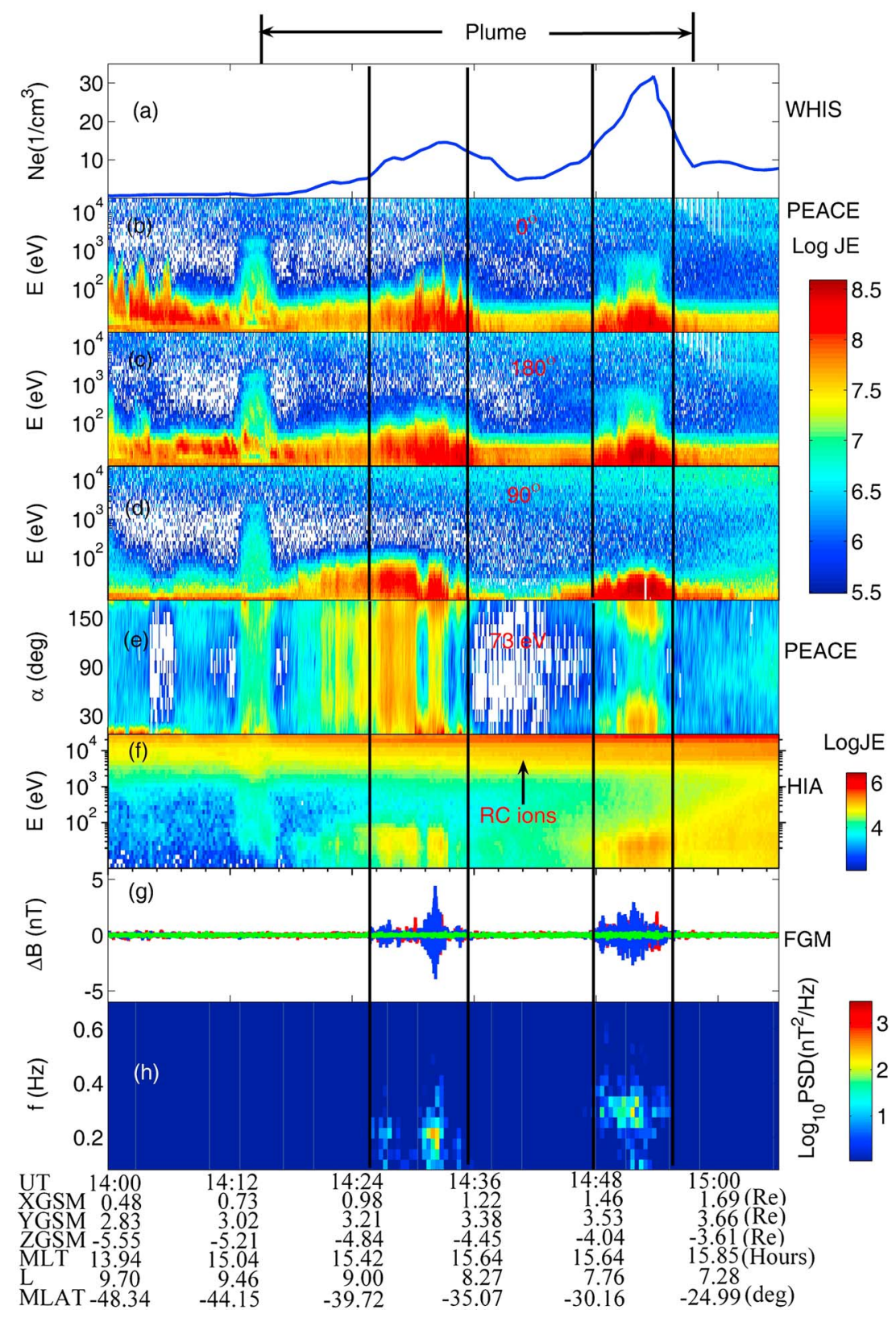

Figure 1. Overview of data from Cluster C1 between 14:00 and 15:06 UT on 18 July 2005. (a) Electron density derived from the electron plasma frequency detected by the WHISPER instrument. (b)-(d) PEACE electron energy-time spectrogram in particle energy flux units at pitch angle of $0^{\circ}, 180^{\circ}$, and $90^{\circ}$, respectively. (e) Pitch angle plot for electron PEACE data at energy of $73 \mathrm{eV}$. (f) HIA omnidirectional energy-time spectrogram in particle flux units (no mass discrimination). (g) Disturbed

magnetic field in the field-aligned coordinate system measured by FGM with a time resolution of $0.1 \mathrm{~s}$ derived by using a $25.6 \mathrm{~s}$ running window. The two perpendicular components $\left(\Delta \mathrm{B}_{\mathrm{t} 1}\right.$ and $\left.\Delta \mathrm{B}_{\mathrm{t} 2}\right)$ and the field-aligned component $\left(\Delta \mathrm{B}_{\mathrm{FA}}\right)$ of perturbed magnetic field in the field-aligned coordinate system are denoted by red, blue, and green solid lines, respectively. (h) Power spectral density (PSD) of the $\Delta \mathrm{B}_{\mathrm{t} 2}$ component of disturbed magnetic field. Black vertical solid lines denote two time intervals of electron heating in the plasmaspheric plume.

As shown in Figure 2b, in comparison with the flux prior to the event (14:42:01-14:42:05 UT), the electron flux obviously enhanced in the energy range of 10-80 eV during the EMIC wave event (14:51:58-14:52:02 UT), implying an electron heating event. Between 14:51:59 UT and 14:52:02 UT, the flux sharply decreased at about $40 \mathrm{eV}$ for the pitch angle of $90^{\circ}$ and gradually decreased for the pitch angle of $0^{\circ}$ and $180^{\circ}$, implying that electron heating is much stronger for the pitch angle of $0^{\circ}$ and $180^{\circ}$ than that for the pitch angle of $90^{\circ}$. 

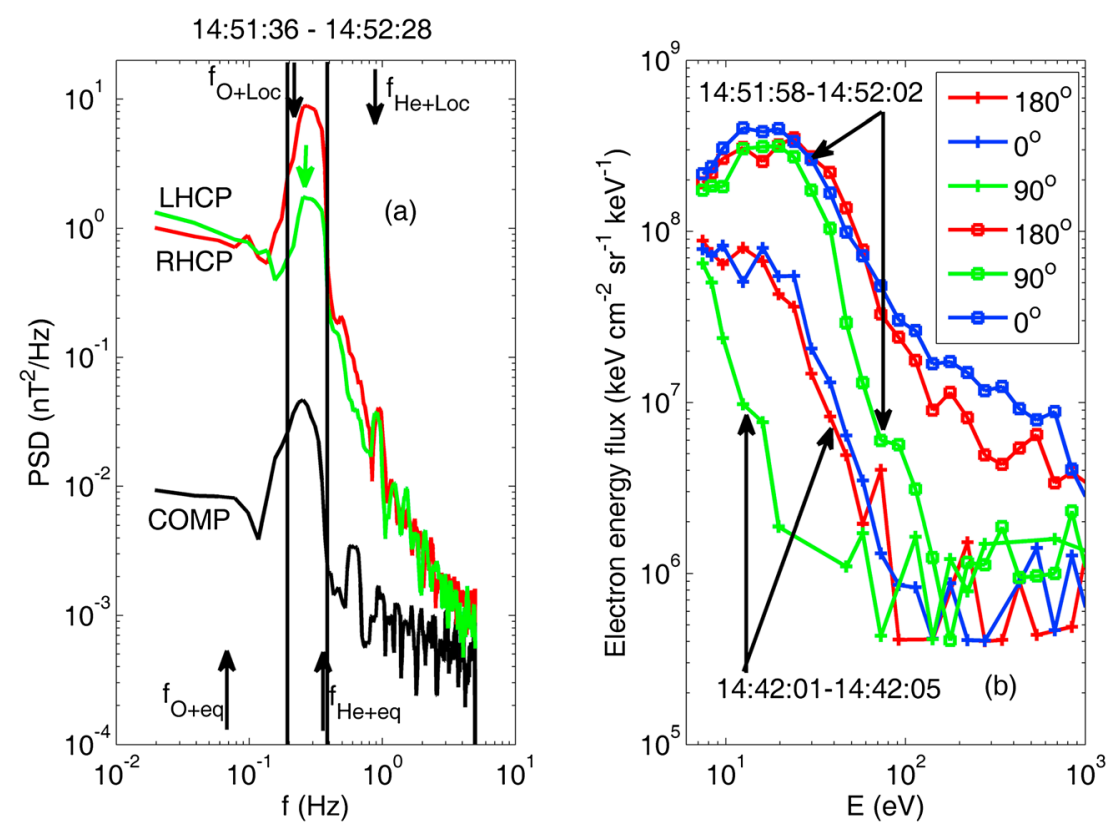

Figure 2. (a) Power spectrum of the disturbed magnetic field measured by FGM of Cluster $\mathrm{C} 1$ in the field-aligned coordinate system for time intervals of 14:51:36-14:52:28 UT selected from data of Figure 1. The power spectrum of left-hand circularized polarization (LHCP) and right-hand circularized polarization (RHCP) and compression (COMP) components in the field-aligned coordinate system is denoted by green, red, and black solid lines, respectively. Vertical black solid lines denote the frequency band of disturbed magnetic field. (b) PEACE electron energy spectra during the electromagnetic ion cyclotron wave event (14:51:58-14:52:02 UT) and just prior to the event (14:42:01-14:42:05). The spectra are shown for pitch angle of $0^{\circ}$ (blue lines), $180^{\circ}$ (red lines), and $90^{\circ}$ (green lines).

As shown in Figures 3a-3c, with amplitude enhancements of perpendicular components of disturbed magnetic field in the field-aligned coordinates between 14:47 and 14:55 denoted by two vertical solid

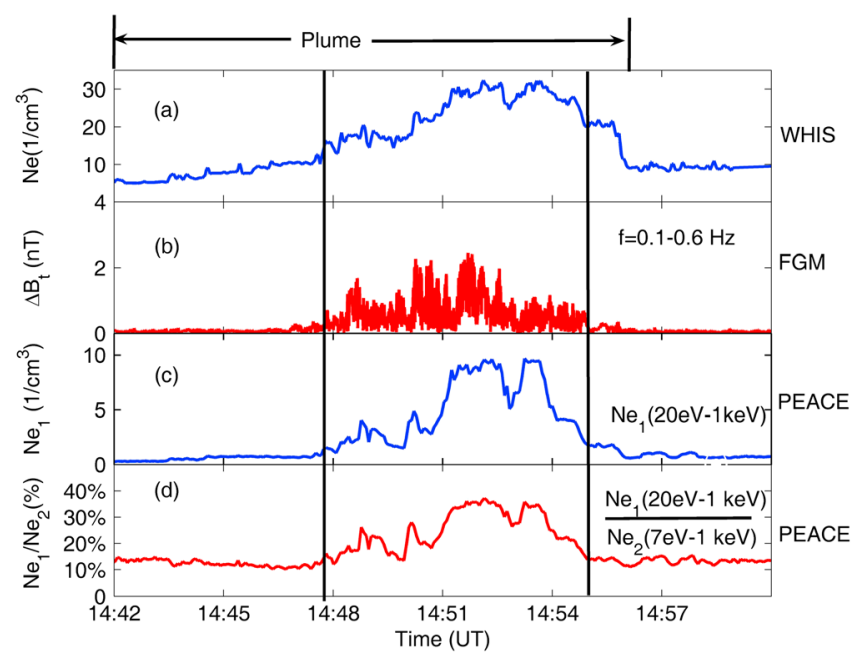

Figure 3. (a) Electron density measured by the WHISPER instrument. (b) Amplitude of perpendicular components $\left(\Delta B_{t}=\sqrt{\Delta B_{t 1}^{2}+\Delta B_{t 2}^{2}}\right)$ of disturbed magnetic field measured by FGM through a band-pass filter with a passband of $0.1-0.6 \mathrm{~Hz}$ in the field-aligned coordinates. (c) Electron density in energy range of $20 \mathrm{eV}-1 \mathrm{keV}$ detected by PEACE. (d) Ratio of electron density in energy range of $20 \mathrm{eV}-1 \mathrm{keV}$ to that in energy range of $7 \mathrm{eV}-1 \mathrm{keV}$ detected by PEACE. Two black vertical solid lines denote enhancements of the electron density in energy range of $20 \mathrm{eV}-1 \mathrm{keV}$. lines, the electron density with energies of $20 \mathrm{eV}-1 \mathrm{keV}$ sharply increased in the outer boundary of the plasmaspheric plume. To be noted, as shown in Figures $3 \mathrm{~b}$ and $3 \mathrm{~d}$, with enhancements of EMIC waves, the ratio of electron density in the energy range of $20 \mathrm{eV}-1 \mathrm{keV}$ to that in energy range of $7 \mathrm{eV}-1 \mathrm{keV}$ increased, implying that EMIC waves heat cold electrons to above $20 \mathrm{eV}$.

\section{Discussion and Conclusion}

In the presence of cold dense ions, the anisotropic RC proton distributions can become unstable to the amplification of EMIC waves [Gary et al., 1995; Liu et al., 2012]. Therefore, it is expected that EMIC waves occur in the region of overlap between plasmaspheric plumes and the ring current [Fraser and Nguyen, 2001; Yuan et al., 2010]. In fact, in Figures 1a, 1f, and 1h, we have observed the EMIC waves in the plasmaspheric 
plume with occurrence of RC ions. On the other hand, ray tracing and path-integrated linear growth calculations have shown that the density irregularities in the plasmaspheric plume can modify the EMIC growth so that EMIC waves can be preferentially excited in the enhancement density ducts on the negative density gradient side [Chen et al., 2009; De Soria-Santacruz et al., 2013]. As shown in Figure 1, EMIC waves mainly occurred in the enhancement density ducts on the negative density gradient side for two substructures of the plasmaspheric plume, in agreement with the previous path-integrated linear growth calculations of EMIC wave growth.

For the second electron heating event denoted by the right two vertical solid lines in Figure 1, Figures 1a-1d and $1 \mathrm{~h}$ show that the plasmaspheric electron heating occurred with enhancements of EMIC waves in the plasmaspheric plume. As shown in Figures $1 b-1 d$ and $2 b$, the electron heating was much stronger for the pitch angle of $0^{\circ}$ and $180^{\circ}$ than for the pitch angle of $90^{\circ}$. Since Landau damping increases the parallel energy of the electrons [Cornwall et al., 1971; Thorne and Horne, 1992], Landau damping of oblique EMIC waves is a reasonable candidate to produce the heated plasmaspheric electron population for the electron heating event.

In order to further confirm that the parallel cold electron heating shown in Figure $2 \mathrm{~b}$ is attributed to the Landau damping of oblique EMIC waves, we calculated the electron resonant energy due to Landau resonant interaction with observed EMIC waves in Figure 2a. The dispersion relationship for electromagnetic waves propagating in a uniform, cold plasma is mentioned in many references [e.g., Stix, 1962],

$$
\begin{array}{cl}
A n^{4}-B n^{2}+C=0 \quad A & =P \cos ^{2} \theta+S \sin ^{2} \theta \quad B=S P\left(1+\cos ^{2} \theta\right)+R L \sin ^{2} \theta \\
C & =P R L \quad S=\frac{(R+L)}{2} \quad n=\frac{c k}{\omega}
\end{array}
$$

where $k, \omega, c$, and $\theta$ denote the wave number, wave frequency, velocity of light, and the wave normal angle, respectively.

The wave coefficients defined by Stix [1962] are

$$
R=1-\sum_{i} \frac{\omega_{p i}^{2}}{\omega} \frac{1}{\omega+\Omega_{i}} \quad L=1-\sum_{i} \frac{\omega_{p i}^{2}}{\omega} \frac{1}{\omega-\Omega_{i}} \quad P=1-\sum_{i} \frac{\omega_{p i}^{2}}{\omega^{2}}
$$

where the sums are over all species including electrons, $\omega_{p i}$ and $\Omega_{i}$ denote the plasma frequency and gyrofrequency with sign for the ith species, respectively.

The condition for Landau resonant interaction between EMIC waves and cold electrons is

$$
\omega-k_{/ /} v_{/ /}=0
$$

where $k_{/ /,} v_{/ /}$denote the parallel wave number and the parallel electron velocity, respectively.

During the interval of 14:51:36-14:52:28, as shown in Figure 3, the local plasma density is $29 \mathrm{~cm}^{-3}$, and the local ambient magnetic field is calculated to be $230 \mathrm{nT}$. The wave normal angle is estimated to $25^{\circ}$ by the minimum variance analysis on the perturbed magnetic field [Song and Russell, 1999]. Since the heating event occurred in a geomagnetic storm, the typical cold ion compositions of $\left[\mathrm{H}^{+}\right]:\left[\mathrm{He}^{+}\right]:\left[\mathrm{O}^{+}\right]=82: 15: 3[$ Grew et al., 2007] for representative storm time are adopted in this letter. Considering ULF waves propagating with a wave normal angle of $25^{\circ}$ with reference to the ambient magnetic field in cold multi-ion plasma, Figure $4 a$ displays the dispersion relationship of ULF waves. As shown in Figure 2a, the band of Pc1 waves denoted by two black vertical solid lines is between the $\mathrm{O}^{+}$ion gyrofrequency $\left(\mathrm{f}_{\mathrm{O}+e q}\right)$ and the $\mathrm{He}^{+}$ion gyrofrequency $\left(\mathrm{f}_{\mathrm{He}+\mathrm{eq}}\right)$ in the equatorial plane but above the local $\mathrm{O}^{+}$ion gyrofrequency $\left(\mathrm{f}_{\mathrm{O}+\mathrm{Loc}}\right)$, implying that those EMIC waves were generated in frequency range on the $\mathrm{He}^{+}$branch in the equatorial plane. As shown in Figures $4 \mathrm{a}$ and $4 \mathrm{~b}$, considering the contribution of cold $\mathrm{O}^{+}$ions to the local dispersion relationship of ULF waves, those EMIC waves generated in frequency range on the $\mathrm{He}^{+}$branch in the equatorial plane can encounter the key points (where the normalized frequency of EMIC waves is equal to $\mathrm{FC}_{\mathrm{He}+}=\mathrm{fC}_{\mathrm{He}_{+}} / \Omega_{\mathrm{H+}}$ ) through the propagation path of EMIC waves from the source region to the location of Cluster 1.

We assume that both the background electron density $\left(29 \mathrm{~cm}^{-3}\right)$ and the wave normal angle $\left(25^{\circ}\right)$ are constant along a field line. For the peak frequency $\left(f_{\text {peakLH }}\right)$ of LH waves denoted by the green arrow in Figure $2 a$ using equations (1)-(3), we calculate the parallel electron resonant energies due to Landau 

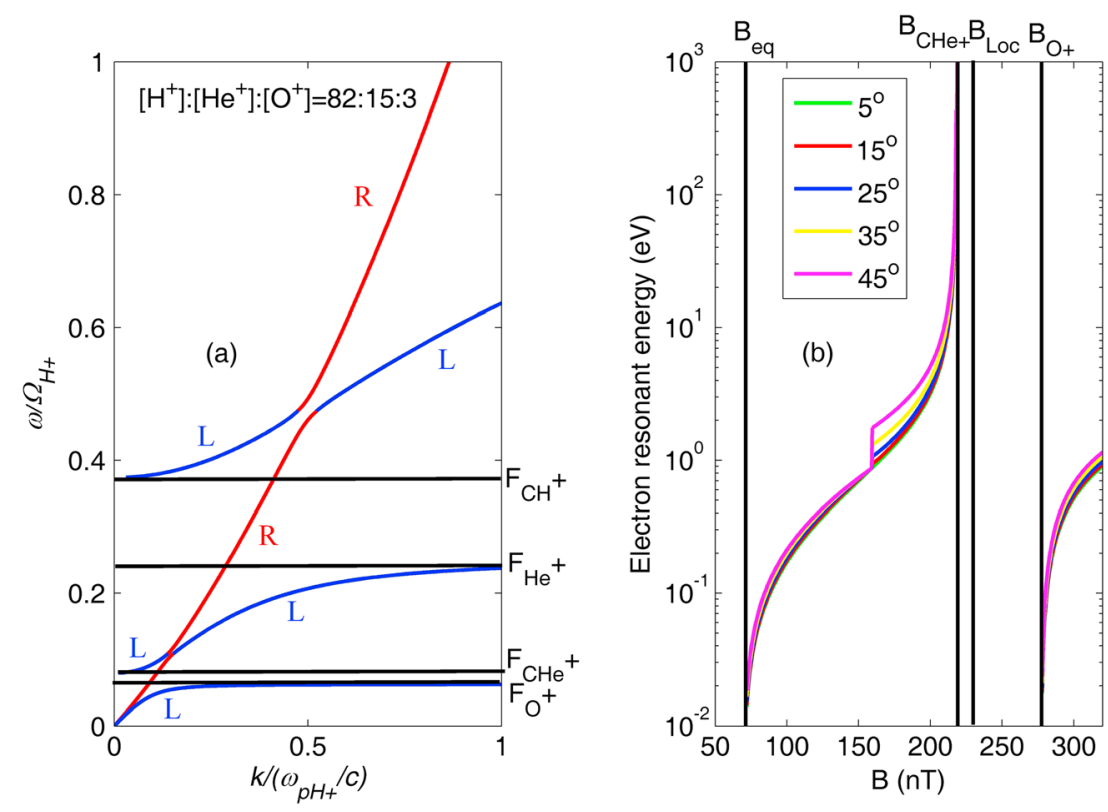

Figure 4. (a) Dispersion relationship for ULF waves propagation with the wave normal angle of $25^{\circ}$ with reference to the ambient magnetic field. Cold plasma with ion compositions of $\left[\mathrm{H}^{+}\right]:\left[\mathrm{He}^{+}\right]:\left[\mathrm{O}^{+}\right]=82: 15: 3$ approximation is assumed. " $\mathrm{R}^{\prime}$ and " $\mathrm{L}$ " denote right-hand and left-hand polarized modes, respectively. Those labels on the right denote normalized frequencies ( $f / \Omega_{\mathrm{H}_{+}}$) with the $\mathrm{H}^{+}$ion gyrofrequency. (b) Parallel electron resonant energy through Landau resonant interaction for the peak frequency of the LH waves denoted by the green arrow in Figure 3 from the equatorial plane to the location of Cluster 3. The green, red, blue, yellow, and black lines denote parallel electron resonant energy with LH waves for $5^{\circ}, 15^{\circ}$ $25^{\circ}, 35^{\circ}$, and $45^{\circ}$, respectively. $B_{\text {eq }}$ and $B_{\text {Loc }}$ denote the magnetic field in the equatorial plane and the location of Cluster 3 , respectively. $\mathrm{B}_{\mathrm{cHe}+}$ and $\mathrm{B}_{\mathrm{O}+}$ denote the magnetic field according to the $\mathrm{He}^{+}$band cutoff frequency and the $\mathrm{O}^{+}$ion gyrofrequency shown in Figure 4a, respectively.

resonant interaction through the propagation path of EMIC waves from the equatorial plane to the location of Cluster 1. The TS05 model is used to calculate the magnetic field from the equatorial plane to the location of Cluster 1 along the magnetic field lines.

Although the wave normal angle may not be a constant during the propagation, the Earth's magnetic field and the negative density gradient of cold densities tend to align the wave normal vector with the magnetic field direction [Chen et al., 2009; De Soria-Santacruz et al., 2013]. Therefore, we calculate parallel electron resonant energies with $\mathrm{LH}$ waves for the wave normal angle of $5^{\circ}, 15^{\circ}, 25^{\circ}, 35^{\circ}$, and $45^{\circ}$. As shown in Figure $4 \mathrm{~b}$, the parallel electron resonant energy increases to more than $100 \mathrm{eV}$ near the magnetic field $\mathrm{B}_{\mathrm{CHe}+}$ according to the cutoff frequency for the $\mathrm{He}^{+}$band.

As shown in Figures $3 b$ and $3 d$, with enhancements of EMIC waves, the ratio of electron density in the energy range of $20 \mathrm{eV}-1 \mathrm{keV}$ to that in the energy range of $7 \mathrm{eV}-1 \mathrm{keV}$ increases, implying that EMIC waves heat cold electrons to above $20 \mathrm{eV}$. Therefore, considering the contribution of cold $\mathrm{O}^{+}$ions to the local dispersion relationship of ULF waves, the energies of heated electrons can reach to tens of eV by Landau resonant interaction between EMIC waves and electrons near the magnetic field $\mathrm{B}_{\mathrm{CHe}}$ according to the cutoff frequency for the $\mathrm{He}^{+}$band. It other words, an obvious electron heating occurs where the frequency of EMIC waves approached to the local cutoff frequency for the $\mathrm{He}^{+}$band on the propagation path. The heated electrons can reach the location of Cluster 1 under the bounce motion, in agreement with observations shown in Figure 1.

In fact, as shown in Figure 4, the local magnetic field is between $\mathrm{B}_{\mathrm{cHe}+}$ and $\mathrm{B}_{\mathrm{O}+}$, meaning that Cluster 1 was located in the cutoff region of the $\mathrm{He}^{+}$band (between $\mathrm{F}_{\mathrm{CHe}}$ and $\mathrm{F}_{\mathrm{O}+}$ as shown Figure 4a). When the ULF waves passed through the cutoff region of the $\mathrm{He}^{+}$band, the $\mathrm{RH}$ polarized component can propagate through the cutoff region, but the LH polarized component can be partially reflected. With enhancements of the ratio of $\mathrm{O}^{+}$density to total ion density, the reflection coefficient of the $\mathrm{LH}$ polarized component increases 
[Johnson and Cheng, 1999; Hu et al., 2010]. Therefore, as shown in Figure 2a, the wave packets are mainly RH polarized during the interval. Since the $\mathrm{RH}$ polarized waves heat cold electrons to less than $10 \mathrm{eV}$ through the propagation path of EMIC waves from the source region to the location of Cluster 1 (not shown here), the electron heating should not be attributed to $\mathrm{RH}$ polarized waves but to $\mathrm{LH}$ polarized waves.

Coulomb collision of plasmaspheric electrons with RC ions is another candidate for producing a heated plasmaspheric electron population [Cole, 1965; Kozyra et al., 1987; Fok et al., 1993]. However, with the calculation method of Fok et al. [1991], for RC protons with energy of $20 \mathrm{keV}$, the relevant scattering time would be $>20$ days for the electron heating event where the electron density is about $30 / \mathrm{cc}$. The timescales of direct Coulomb collisional heating during the interval was too long to effectively produce the heated plasmaspheric electron population. On the other hand, due to Coulomb collision interactions, the pitch angle distribution of heated plasmaspheric electron population should be isotropic [Kozyra et al., 1997], which is not consistent with our observations. Therefore, Coulomb collision interaction of the plasmaspheric electrons with the RC ions is not a candidate to produce the heated electron population shown in Figure 1. Although kinetic Alfvén waves are also suggested to directly accelerate plasmaspheric electrons into the ionosphere through the parallel electric field associated with the waves [Hasagawa and Mima, 1978], for the case of this paper, kinetic Alfvén waves were not observed during the interval of the electron heating.

With observations of Cluster C1, we have presented in situ evidence of plasmaspheric electron heating in the plasmaspheric plume. The major conclusions are as follows:

1. EMIC waves were mainly observed in the enhancement density ducts on the negative density gradient side for two substructures of the plasmaspheric plume, in agreement with the previous theoretical calculations of EMIC wave growth.

2. In the outer boundary of the plasmaspheric plume, two electron heating events were accompanied by enhancements of electromagnetic ion cyclotron (EMIC) waves. Electron heating is much stronger for the pitch angle of $0^{\circ}$ and $180^{\circ}$ than for the pitch angle of $90^{\circ}$. Theoretical calculations of the Landau resonant interaction between electrons and observed EMIC waves demonstrate that Landau damping of oblique EMIC waves is a reasonable candidate to heat cold electrons in the presence of $\mathrm{O}^{+}$ions in the outer boundary of the plasmaspheric plume. Therefore, this observation is considered in situ evidence of plasmaspheric electron heating through Landau damping of EMIC waves in plasmaspheric plumes. In order to better demonstrate the relation between EMIC waves, cold plasmaspheric electron heating, and temperature enhancements of the topside ionospheric electrons, conjugate observations of multiple satellites (such as the Cluster, THEMIS, and DMSP satellites) are necessary, which will be discussed in a future study.

\section{Acknowledgments}

We thank the Cluster teams and Cluster Active Archive (CAA) for the high-quality data and successful operation. This research is supported by the National Natural Science Foundation of China (41174140, 41204112, 41221003, 41374168), research Fund for the Doctoral Program of Higher Education of China (20110141110043), and Program for New Century Excellent Talents in University (NCET-13-0446).

The Editor thanks two anonymous reviewers for assistance in evaluating this manuscript.

\section{References}

Brace, L. H., R. C. Chappell, M. O. Chandler, R. H. Comfort, J. L. Horwitz, and W. R. Hoegy (1988), F region electron temperature signatures of the plasmapause based on Dynamics Explorer 1 and 2 measurements, J. Geophys. Res., 93, 1896-1908.

Chandra, S. E., J. Maier, and P. Stubbe (1972), The upper atmosphere as regulator of subauroral red arcs, Planet. Space Sci., $20,461-472$.

Chen, L., R. M. Thorne, and R. B. Horne (2009), Simulation of EMIC wave excitation in a model magnetosphere including structured highdensity plumes, J. Geophys. Res., 114, A07221, doi:10.1029/2009JA014204.

Cole, K. D. (1965), Stable auroral red arcs, sinks for energy of Dst main phase, J. Geophys. Res., 70, 1689-1706.

Cole, K. D. (1975), Coulomb collisions of ring current particles: Indirect source of heat for the ionosphere, Tech. Rep. X-621-75-108, NASA Goddard Space Flight Cent., Greenbelt, Md.

Cornwall, J. M., F. V. Coroniti, and R. M. Thorne (1971), Unified theory of SAR arc formation at the plasmapause, J. Geophys. Res., 76, 4428-4445.

Darrouzet, F., J. De Keyser, P. M. E. Décréau, F. El Lemdani-Mazouz, and X. Vallières (2008), Statistical analysis of plasmaspheric plumes with Cluster/WHISPER observations, Ann. Geophys., 26, 2403-2417.

de Soria-Santacruz, M., M. Spasojevic, and L. Chen (2013), EMIC waves growth and guiding in the presence of cold plasma density irregularities, Geophys. Res. Lett., 40, 1940-1944, doi:10.1002/grl.50484.

Erlandson, R. E., T. L. Aggson, W. R. Hogey, and J. A. Slavin (1993), Simultaneous observations of subauroral electron temperature enhancements and electromagnetic ion cyclotron waves, Geophys. Res. Lett., 29, 1723-1726.

Fok, M. C., J. U. Kozyra, A. F. Nagy, and T. E. Cravens (1991), Lifetime of ring current particles due to Coulomb collisions in the plasmasphere, J. Geophys. Res., 96, 7861-7867.

Fok, M. C., J. U. Kozrya, A. F. Nagy, C. E. Rasmussen, and G. V. Khazanov (1993), Decay of equatorial ring current ions and associated aeronomical consequences, J. Geophys. Res., 98, 19,381-19,393.

Fraser, B. J., and T. S. Nguyen (2001), Is the plasmaspause a preferred source region of electromagnetic ion cyclotron waves in the magnetosphere?, J. Atmos. Sol. Terr. Phys., 63, 1225-1247.

Gary, S. P., M. F. Thomsen, L. Yin, and D. Winske (1995), Electromagnetic proton cyclotron instability: Interactions with magnetospheric protons, J. Geophys. Res., 100(A11), 21,961-21,972.

Grew, R. S., F. W. Menk, M. A. Clilverd, and B. R. Sandel (2007), Mass and electron densities in the inner magnetosphere during a prolonged disturbed interval, Geophys. Res. Lett., 34, L02108, doi:10.1029/2006GL028254. 
Hasagawa, A., and K. Mima (1978), Anomalous transport produced by kinetic Alfvén wave turbulence, J. Geophys. Res., 83, $1117-1123$. Hu, Y., R. E. Denton, and J. R. Johnson (2010), Two-dimensional hybrid code simulation of electromagnetic ion cyclotron waves of multi-ion plasmas in a dipole magnetic field, J. Geophys. Res., 115, A09218, doi:10.1029/2009JA015158.

Johnson, J. R., and C. Z. Cheng (1999), Can ion cyclotron waves propagate to the ground?, Geophys. Res. Lett., 26, 671-674.

Kozyra, J. U., E. G. Shelley, R. H. Comfort, L. H. Brace, T. E. Cravens, and A. F. Nagy (1987), The role of ring current O + in the formation of stable auroral red arcs, J. Geophys. Res., 92, 7487-7502.

Kozyra, J. U., A. F. Nagy, and D. W. Slater (1997), High-altitudes energy source(s) for stable auroral red arcs, Rev. Geophys., 35, 155-190.

Lanzerotti, L. J., A. Hasagawa, and C. G. Maclennan (1978), Hydromagnetic waves as a cause of a SAR arc event, Planet. Space Sci., 26, 777-783.

Liu, Y. H., B. J. Fraser, and F. W. Menk (2012), Pc2 EMIC waves generated high off the equator in the dayside outer magnetosphere, Geophys. Res. Lett., 39, L17102, doi:10.1029/2012GL053082.

Lundblad, J. Å., and F. Søraas (1978), Proton observations supporting the ion cyclotron wave heating theory of SAR arc formation, Planet. Space Sci., 26, 245-254.

Mishin, E. V., and W. J. Burke (2005), Stormtime coupling of the ring current, plasmasphere, and topside ionosphere: Electromagnetic and plasma disturbances, J. Geophys. Res., 110, A07209, doi:10.1029/2005JA011021.

Owen, C. J., et al. (2001), Cluster PEACE observations of electrons during magnetosphere flux transfer events, Ann. Geophys., 19, 1509-1522. Song, P., and C. T. Russell (1999), Time series data analyses in space physics, Space Sci. Rev., 87, 387-463, doi:10.1023/A:1005035800454

Stix, T. H. (1962), The Theory of Plasma Waves, McGraw-Hill, New York.

Thorne, R. M., and R. B. Horne (1992), The contribution of ion-cyclotron waves to electron heating and SAR-arc excitation near the storm-time plasmapause, Geophys. Res. Lett., 19, 417-420.

Tsyganenko, N. A., and M. I. Sitnov (2005), Modeling the dynamics of the inner magnetosphere during strong geomagnetic storms, J. Geophys. Res., 110, A03208, doi:10.1029/2004JA010798.

Vallat, C., et al. (2004), First comparisons of local ion measurements in the inner magnetosphere with ENA magnetospheric image inversions: Cluster-CIS and IMAGE-HENA observations, J. Geophys. Res., 109, A04213, doi:10.1029/2003JA010224.

Yuan, Z., X. Deng, X. Lin, Y. Pang, M. Zhou, P. M. E. Décréau, J. G. Trotignon, E. Lucek, H. U. Frey, and J. Wang (2010), Link between EMIC waves in a plasmaspheric plume and a detached sub-auroral proton arc with observations of Cluster and IMAGE satellites, Geophys. Res. Lett., 37, L07108, doi:10.1029/2010GL042711.

Yuan, Z., Y. Xiong, Y. Pang, M. Zhou, X. Deng, J. G. Trotignon, E. Lucek, and J. Wang (2012), Wave-particle interaction in a plasmaspheric plume observed by a Cluster satellite, J. Geophys. Res., 117, A03205, doi:10.1029/2011JA017152.

Zhou, Q., F. Xiao, C. Yang, Y. He, and L. Tang (2013), Observation and modeling of magnetospheric cold electron heating by electromagnetic ion cyclotron waves, J. Geophys. Res. Space Physics, 118, 6907-6914, doi:10.1002/2013JA019263. 